\title{
Efficacy of sand columns to increase the sub-soil moisture content of clay
}

\author{
Mousa F. Attom ${ }^{1} \cdot$ Zahid Khan $^{1} \cdot$ Ramesh Vandanapu ${ }^{2}$
}

Received: 22 November 2019 / Accepted: 17 April 2020 / Published online: 29 April 2020

(c) Springer Nature Switzerland AG 2020

\begin{abstract}
Many countries all over the world were suffering from severe shortage of water and this shortage can be solved using varieties of practices. The research presents a novel technique to increase the subsurface moisture in clayey soil by increasing the infiltration rates through vertical sand columns. In this research, two sand columns with different diameters (diameter $=50 \mathrm{~mm}$ and $100 \mathrm{~mm}$ ) were constructed in the centre of a clay placed in two identical cylindrical containers made of steel (diameter $=1000 \mathrm{~mm}$; height $=700 \mathrm{~mm}$ ). A water layer with height of $30 \mathrm{~mm}$ was added to the top of the soil and allowed to percolate. Water content was determined at different depths and radial distances from the sand column after complete infiltration of water. The results showed that water content in clay increases with depth and decreases with increase in the radial distance from the sand column. Larger diameter of sand column resulted in higher values of water content at the same depths and radial distances with remarkable increase from 9 (for $50-\mathrm{mm}$ diameter) to $16 \%$ (100-mm diameter) noticed at 550-mm depth and 450-mm radial distance. The promising performance of sand column was further found to be improved in terms of increasing the moisture content of clay in the path of choice by creating an obstruction to the water flow in opposite direction. This increase in moisture content was particularly noteworthy at greater depth $(450 \mathrm{~mm})$ and radial distance $(550 \mathrm{~mm})$ with increase from 9 to $20 \%$ and 16 to $26 \%$, respectively, for 50 -mm diameter and 100-mm diameter sand columns. Thus, the proposed methodology was found to be useful to increase the rate of percolation in low permeable clays in areas of less rainfall.
\end{abstract}

Keywords Fertile soil · Sub-soil moisture $\cdot$ Sand columns · Permeability

\section{Introduction}

Fertile soils like clays that retain moisture for the growth of vegetation are available in many regions all over the world. However, many countries are suffering from scarcity of water due to less rainfall and leading to limited usage of fertile lands. Many researchers all over the world have suggested various ways of harvesting water for many uses like drinking, washing, growing plants, etc. Out of all soil types, clayey soils are known for their fertility and retaining moisture. However, nowadays, natural rainfalls are decreasing not only in terms of frequency but also duration, leading to less time availability for the water to seep through the soil. As clays are low permeable soils, the time required for water to retain on its surface shall be more allowing enough duration for fully permeate through. Many researchers [1-4] in the past have attributed the swelling properties to water retention capacity of soil. Also, the permeability of clays depends of various properties like initial moisture content, initial dry density, initial porosity, and boundary conditions [5-10]. In addition, many factors like ground profile, topography of the area, exposure to increased temperatures are main water losing causes for water not being able to seep through the soil.

Ramesh Vandanapu, ramesh.vandanapu@gmail.com; rvandanapu@amityuniversity.ae; Mousa F. Attom, mattom@aus.edu; Zahid Khan, zhkhan@aus.edu | ${ }^{1}$ Department of Civil Engineering, American University of Sharjah, Sharjah, UAE. ${ }^{2}$ Amity University, Dubai, UAE. 
Different techniques have been used in the past for water harvesting and to increase the moisture contentment of the sub-soil. Sand ditches were investigated and proven to be an efficient practice for water harvesting [11, 12]. This study showed that the rainfall storage increased up to $73 \%$ compared with $45 \%$ in the same control area. An older practice was obtained by using pre-treated catchment and micro-catchment areas [13]. A sustainable solution of using the house roof was also investigated for water harvesting [14]. This technique proved to be a practical and doable technique for water harvesting. Another old method of water harvesting was done by the standard contour ridges [15]. A recent study of three in-field water harvesting technologies namely infiltration pits, fanya juus, and contour ridges with cross ties were conducted for water harvesting [16]. The study concluded that the three techniques showed a very good increase in water harvesting compared to control land. Within the literature reviewed, it was noticed that most techniques proposed were associated with containment of water without letting to escape. But, in arid and semi-arid regions where temperatures are high combined with very less rainfall, it becomes necessary not only to retain the water but also let seep into the ground at the earliest possible time. This necessitates either determination or accurate estimation of soil permeability using index tests. Permeability of soil majorly depends on gradation characteristics and shape of soil grains [17-20]. Hence, in this research, an effort was made to develop a new technique that accelerates the penetration of water into clayey grounds. For this purpose, a steel cylindrical mould was taken and filled with clay. At the centre of the mould, a very loose sand column was manually inserted and its efficacy verified in accelerating the permeation of water inside the clay. Finally, various conclusions were drawn on variation of retained/absorbed moisture content in clay at different depths in the mould as well as radial distances from the sand column.

\section{Experimental study}

In this study, in order to accelerate the percolation of water in low permeable clays, a sand column was inserted. At the start i.e. case-1, the experimental set-up (Fig. 1) consists of cylindrical mould made of $1.5-\mathrm{mm}$ thick steel having height and diameter as $700 \mathrm{~mm}$ and $1000 \mathrm{~mm}$, respectively. Initially, a clay layer of $50 \mathrm{~mm}$ was placed at the bottom. Thereafter, a 1-mm thick plastic pipe of sufficient length with suitable diameter $(50-\mathrm{mm}$ and $100-\mathrm{mm}$ diameter as required) was placed vertically at the centre of the mould and clay filled all around the space between the pipe and mould to a height of $550 \mathrm{~mm}$. Knowing the dry density $\left(15 \mathrm{kN} / \mathrm{m}^{3}\right)$ of clay soil and moisture content $(18 \%)$

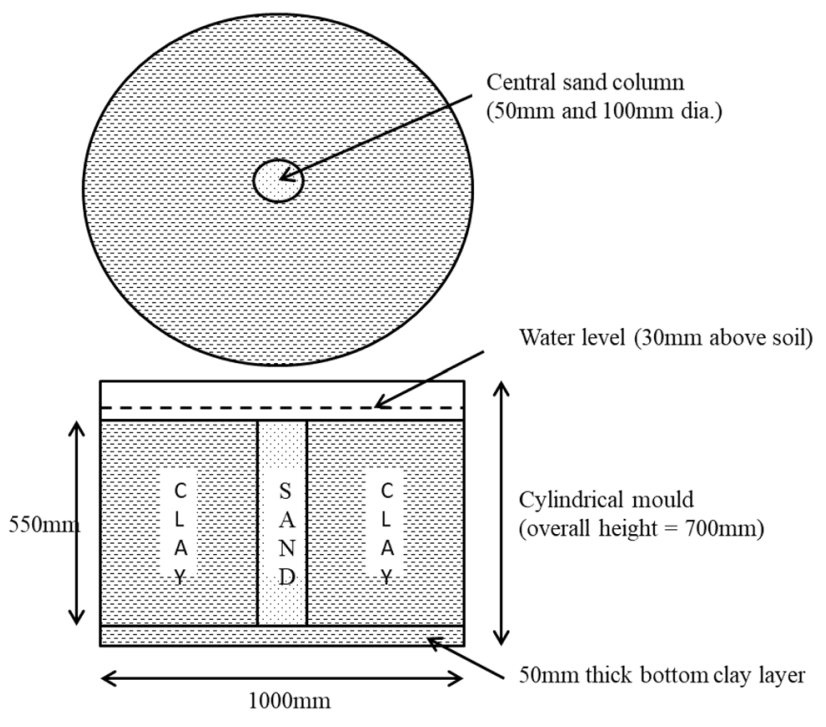

Fig. 1 Typical details of cylindrical container used for experimentation (case-1)

Table 1 Properties of soils used

\begin{tabular}{llll}
\hline Soil type & Property & Unit & Value \\
\hline Clay & Liquid limit & $\%$ & 41 \\
& Plastic limit & $\%$ & 26 \\
& Plasticity index & $\%$ & 15 \\
& Specific gravity & - & 2.67 \\
Sand & $D_{85}$ & $\mathrm{~mm}$ & 2.00 \\
& $D_{60}$ & $\mathrm{~mm}$ & 0.90 \\
& $D_{30}$ & $\mathrm{~mm}$ & 0.20 \\
& $D_{10}$ & $\mathrm{~mm}$ & 0.08 \\
\hline
\end{tabular}

$D$ refers to $\%$ finer than, e.g. $D_{85}=2.00 \mathrm{~mm}$ indicates $85 \%$ of the soil is finer than $2.00 \mathrm{~mm}$

of clay, bulk density was calculated. Once the weight of soil required to be filled in mould was calculated using the bulk density and volume of mould to be occupied by clay, it was placed in the mould and compacted up to the required level by static compaction technique. Thereafter, sand was filled in the pipe in very loose state and slowly removed from the mould. This ensures the formation of sand column at the centre of clay. Properties of sand and clay used in this research can be seen in Table 1 .

The study was conducted using two different diameters of sand columns i.e. $50 \mathrm{~mm}$ and $100 \mathrm{~mm}$. Thereafter, water was slowly poured on the top of soil up to a height of $30 \mathrm{~mm}$ above the soil and allowed sufficient time to percolate into the soil till no water was seen on the top or no further percolation noticed. Though water has been percolated in few hours, adequate time ( $48 \mathrm{~h}$ ) was allowed for the water to seep freely. Subsequently, 
moisture contents were measured at 9 different locations in the mould; at three different depths $150 \mathrm{~mm}, 350 \mathrm{~mm}$, and $550 \mathrm{~mm}$ below the soil surface and at a distance of $50 \mathrm{~mm}, 250 \mathrm{~mm}$, and $450 \mathrm{~mm}$ at each depth from the face of sand column. Sufficient care has been taken in keeping the mould on level surface to ensure the water not to move influentially in any particular direction. To ensure this, few samples were taken randomly and diametrically opposite to sand column, moisture content measured and confirmed the equal spread of water irrespective of any direction from the face of sand column. At the end, it was noticed that water seeped in the clay almost uniformly in all directions. Also, enough precautions were taken such that soil does not mix randomly while samples are taken from the mould for determining the moisture content.

However, in agricultural lands especially at the outer edge of the areas, there would be no requirement of water to be seeped in all directions, and it will be particularly necessary to seep most of the water in the direction in which plants exist. These conditions stand true even in agricultural lands with plantations at far apart, where most of the irrigated water shall be directed towards where plants exist. For this purpose, a modification has been made in the experimental set-up (case-2) shown in Fig. 1 to ensure that more water seeps in one direction i.e. practically the direction of choice in which plants exist. This modification includes insertion of the central pipe that has been vertically cut into two equal halves instead of solid pipe. Once sand was filled in the central pipe, one vertical half of the pipe was removed while the other half was in the mould, which ensure the maximum flow of water in the direction in which pipe does not exist (Fig. 2).

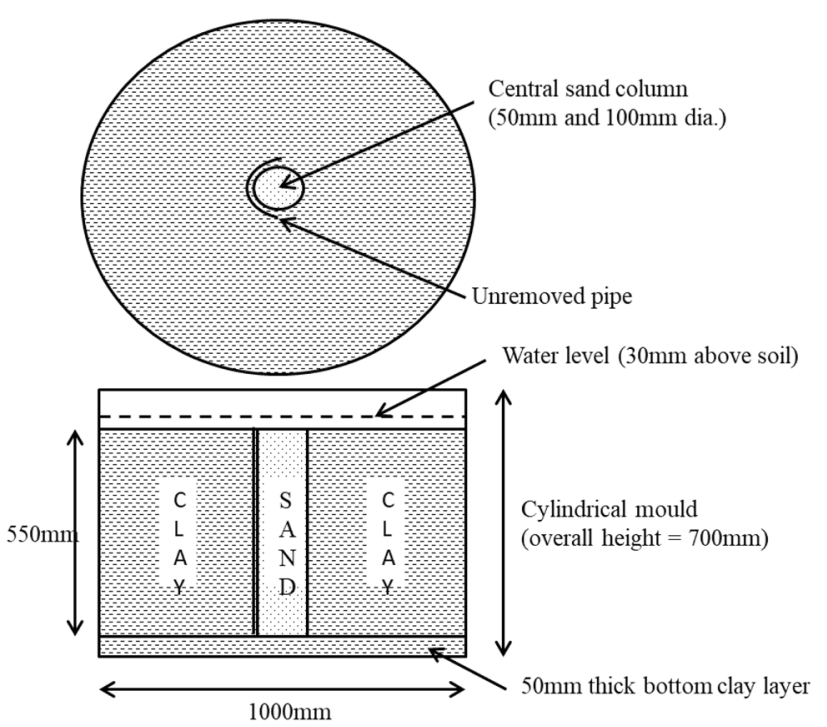

Fig. 2 Typical details of cylindrical container used for experimentation (case-2)
Finally, various graphs were plotted and understood in both cases the influence of diameter of sand column, depth of penetration, and distance from the sand column on the moisture content of clay as seen in the following section.

\section{Results and discussions}

Based on the tests conducted, the results were plotted, and an effort was made to understand the influence of various parameters on the moisture content at different depths in the mould and different distances from the central sand column.

\subsection{Influence of depth on moisture content}

It can be seen from Figs. 3, 4 that there was an increase in moisture content with increase in depth. This was observed in both the sizes of sand columns of both cases experimented in this research. This could be attributed to the presence of high permeable sand column with in soil of low permeability that allowing the water to permeate at a faster rate. Also, it was noteworthy that there was dramatic increase in moisture content at larger depths ( $250 \mathrm{~mm}$ and $450 \mathrm{~mm}$ ) of case- 2 in comparison with case1 , out of which high improvement was noted at $450-\mathrm{mm}$ depth. The increase in moisture content in case- 2 was because of blockage of water movement towards one side of the mould that allows more water to permeate in the direction where the pipe was removed. Also, this was attributable to the fact that water once entered the sand column had permeated vertically downwards due to gravity and reached to lower part of mould and permeated laterally.

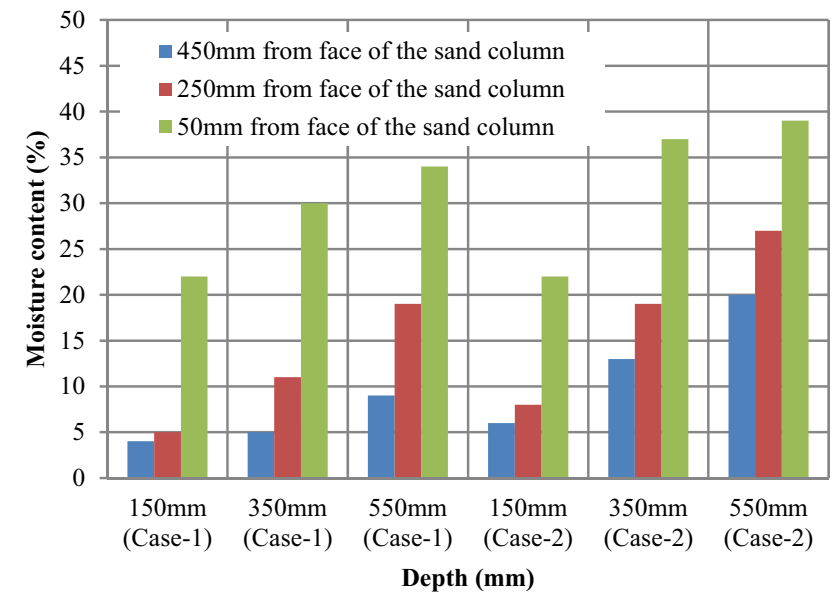

Fig. 3 Variation of moisture content with depth (50-mm diameter sand column) 


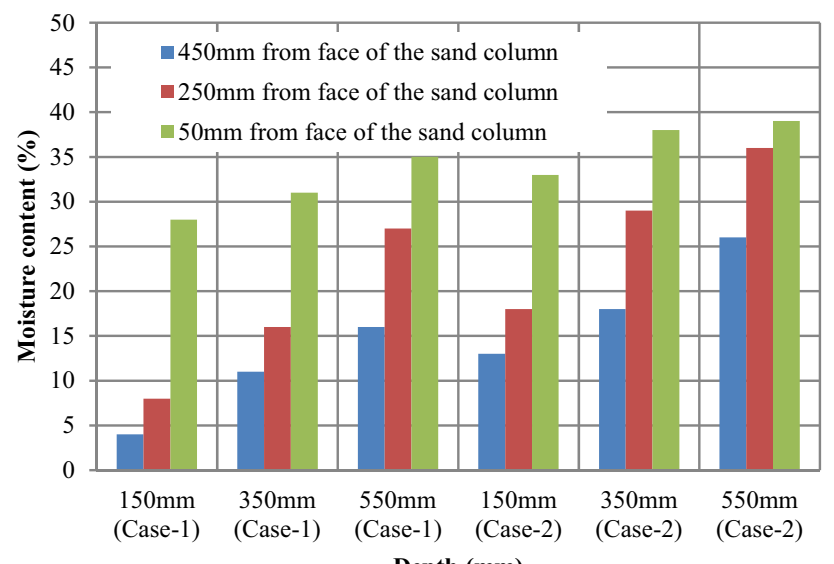

Depth (mm)

Fig. 4 Variation of moisture content with depth (100-mm diameter sand column)

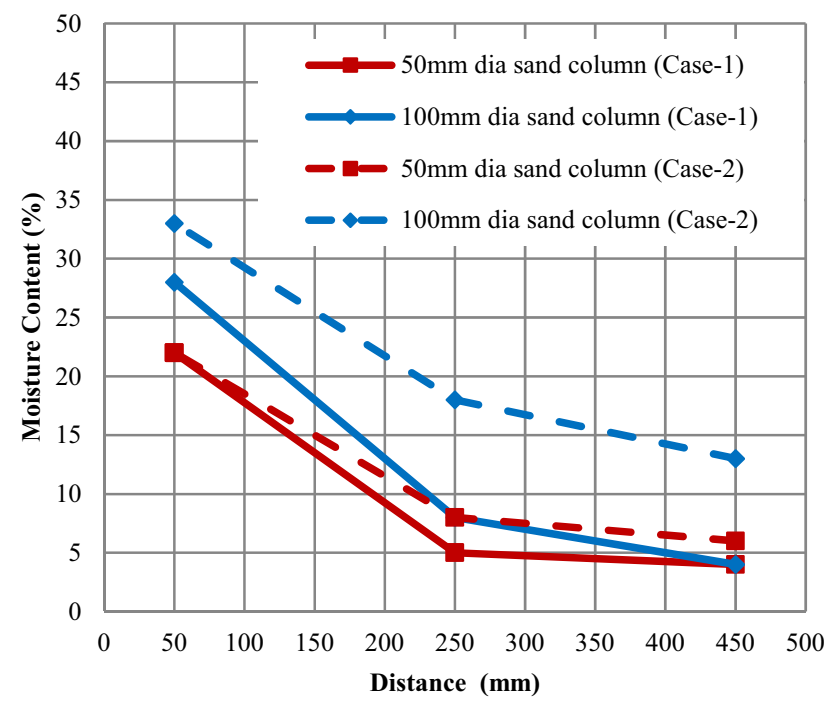

Fig. 5 Variation between moisture content at 150-mm depth with distance from sand column

\subsection{Effect of sand column size on moisture content at various depths}

It was observed from Figs. 5, 6, 7, for both the sand column sizes tried, there was a decrease in moisture content with increase in distance from the sand column.

However in most cases, increase in moisture content was noticed with increase in diameter of the sand column from 50 to $100 \mathrm{~mm}$. For case-1, as seen in Fig. 5 that the moisture content at shallow depth $(150 \mathrm{~mm}$ below) was very less $(4 \%)$ at greater distance $(450 \mathrm{~mm})$. This could be attributed the tendency of water to move downwards by following gravity by the time it reaches to edge of the mould. However, in case-2, significant improvement was

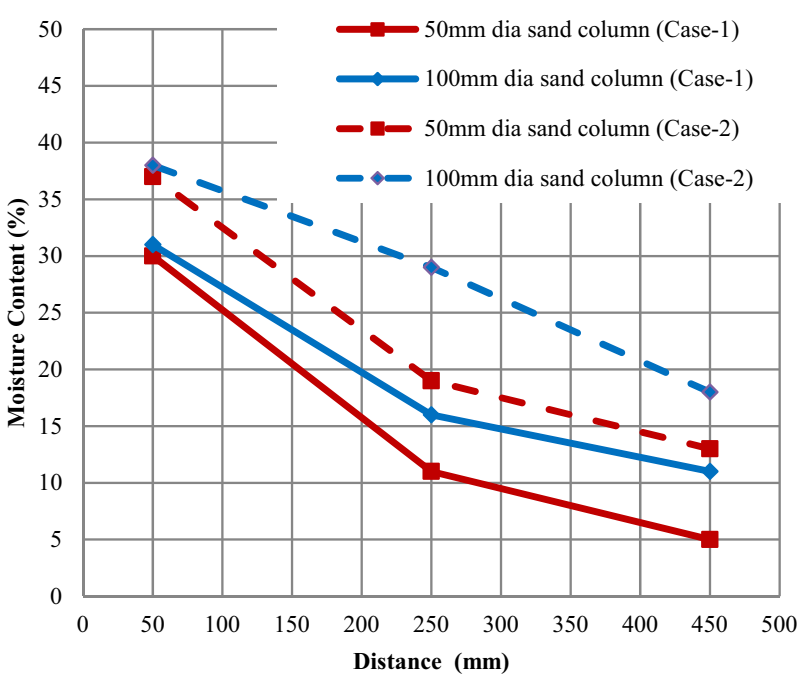

Fig. 6 Variation between moisture content at 350-mm depth with distance from sand column

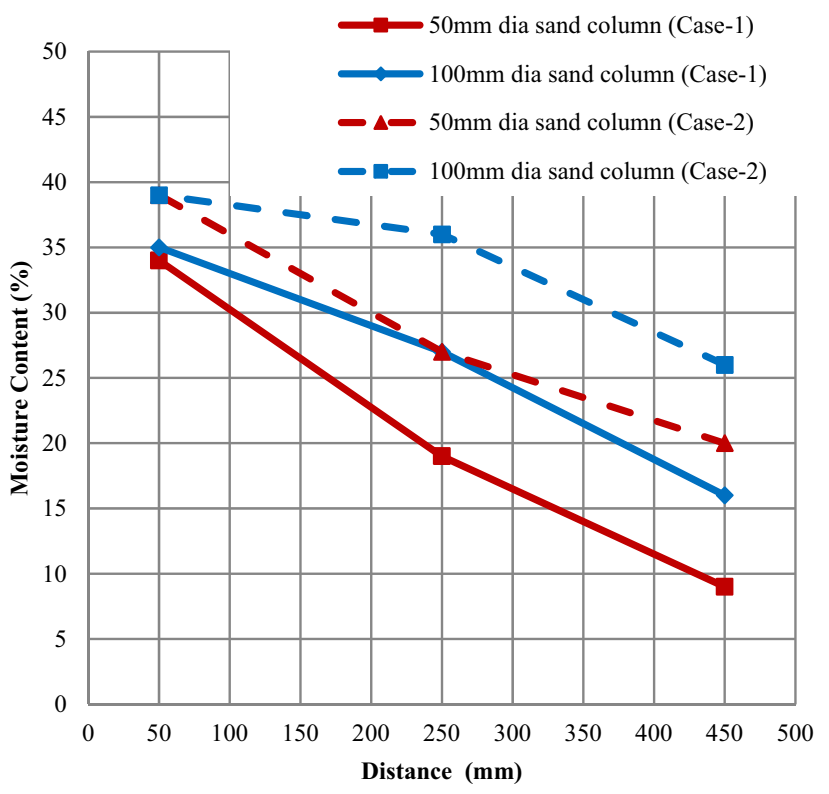

Fig. 7 Variation between moisture content at 550-mm depth with distance from sand column

noticed in moisture contents at larger distances from the sand column. Similar observations were noticed in Figs. 6 , 7. This was due to obstruction for the flow of water due to vertical half of the pipe left in mould. But for $50-\mathrm{mm}$ diameter sand column in case-1, such improvement was not noticed at greater distance $(450 \mathrm{~mm})$ at shallow depth $(150 \mathrm{~mm})$. It was because the water was tending to move downward in the sand column following gravity and low permeability of clay for surface water to vertically seep inside. 


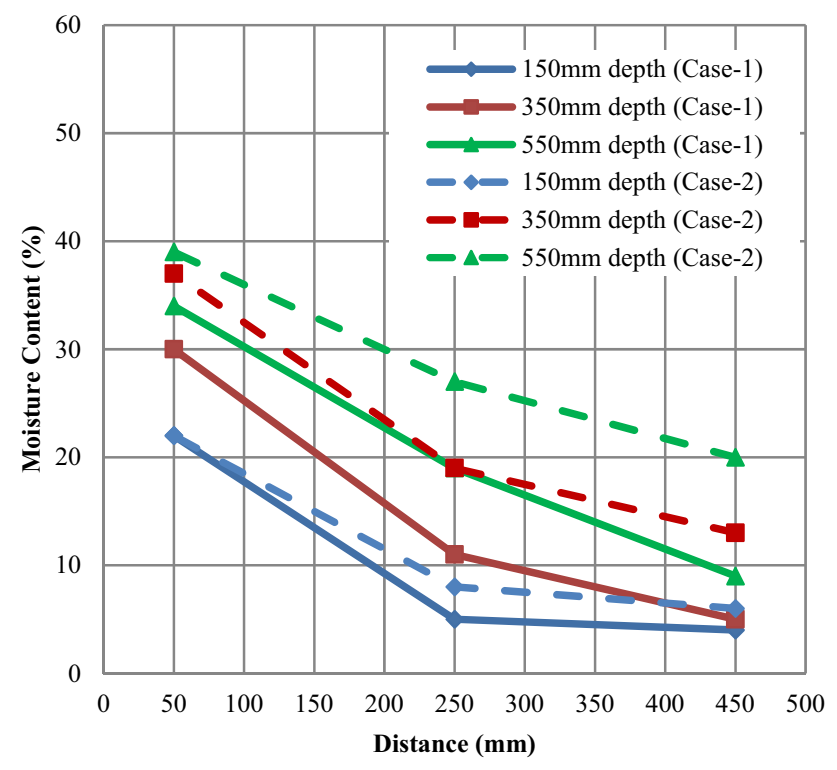

Fig. 8 Variation of moisture content with distance at various depths (50-mm diameter sand column)

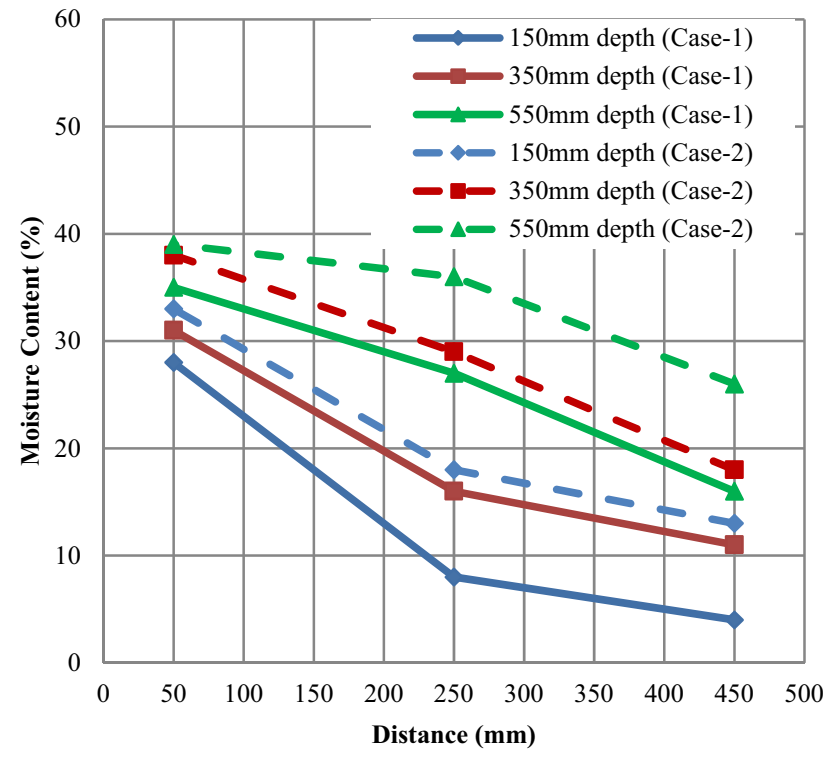

Fig. 9 Variation of moisture content with distance at various depths (100-mm diameter sand column)

\subsection{Effect of distance on moisture content at various depths}

As seen from Figs. 8, 9, for both sand column sizes used, there was an increase in moisture content with increase in depth. However, the movement of moisture was more pronounced in 100-mm diameter sand column in comparison with 50-mm diameter.
It was also observed that though there was no remarkable increase in moisture contents near (50-mm distance) the sand columns irrespective of the sand column size, in case-1, there was considerable increase (9-16\%) observed at greater distance $(450 \mathrm{~mm})$ and depth $(550 \mathrm{~mm})$ with increase in diameter of sand column from 50 to $100 \mathrm{~mm}$. In addition, it was noteworthy that by not removing the vertical half of the pipe in case-2, an increase in moisture content was noticed from 9 to $20 \%$ and 16 to $26 \%$ for 50-mm diameter and 100-mm diameter sand columns, respectively.

Techniques proposed by earlier researchers in the context of water conservation by various methods like ditches $[11,12]$, catchments [13], contour ridges [15], etc. were focussed majorly on saving water without escaping from the required location, but was least emphasized on accelerating the percolation of water into ground as soon as received on the ground surface from rainfall. The method proposed as part of this research can used either in combination or alone with the previously proposed methods by different researchers, but the emphasis was majorly on percolating the water into the ground at faster rate using sand columns in a low permeability grounds, because evaporation losses are high in arid and semi-arid regions where temperatures are usually high and scanty rainfall.

\section{Conclusions}

A simple yet innovative technique was tried as part of this research and found successful in increasing the speed at which water seeps into the grounds of low permeability (clay) with the help of soil columns constructed with high permeability material (sand). This method would be especially useful at places where plants need to be grown in regions where high temperatures exist throughout the year combined with very low rainfall. Based on the results obtained from the experiments conducted, it was noticed that moisture content of the clayey soil increases with increase in depth, regardless of the sand column size. In addition, decrease in moisture content was noticed with increase in radial distance from the sand column. On the other hand, with increase in diameter of the sand column from 50 to $100 \mathrm{~mm}$, considerable increase in moisture content was noticed from 9 to $16 \%$ particularly at greater radial distance $(550 \mathrm{~mm})$ and depth $(450 \mathrm{~mm})$ from the sand column. Also, with a simple modification in the proposed method, when water flow was obstructed in a particular direction, water contents increased in the opposite direction. This was also predominantly noticed at greater depth $(450 \mathrm{~mm})$ and radial distance $(550 \mathrm{~mm})$ with increase from 9 to $16 \%$ for $50-\mathrm{mm}$ diameter sand column and from 16 to $26 \%$ for $100-\mathrm{mm}$ diameter sand column. 
Thus, insertion of sand columns into low permeable clays helped not only in accelerating the water movement down into the ground but also in increasing the sub-soil moisture at greater depths and radial distances.

\section{Compliance with ethical standards}

Conflict of interest On behalf of all authors, the corresponding author states that there is no conflict of interest.

\section{References}

1. Cui YJ, Tang AM, Loiseau C, Delage P (2008) Determining the unsaturated hydraulic conductivity of a compacted sand-bentonite mixture under constant-volume and free-swell conditions. Phys Chem Earth 33(1):462-471. https://doi.org/10.1016/j. pce.2008.10.017

2. Pierre $D$ (2006) Some microstructure effects on the behavior of compacted swelling clays used for engineered barriers. Chin J Rock Mech Eng 25:721-732

3. Siemens G, Blatz JA (2009) Evaluation of the influence of boundary confinement on the behavior of unsaturated swelling clay soils. Can Geotech J 46(3):339-356. https://doi.org/10.1139/ T08-125

4. Ye WM, Cui YJ, Qian LX, Chen B (2009) An experimental study of the water transfer through confined compacted $\mathrm{GMZ}$ bentonite. Eng Geol 108(3-4):169-176. https://doi.org/10.1016/j.engge 0.2009 .08 .003

5. Cho WJ, Lee JO, Chun KS (1999) The temperature effects on hydraulic conductivity of compacted bentonite. Appl Clay Sci 14(1-3):47-58. https://doi.org/10.1016/S0169-1317(98)00047-7

6. Didier G, Bouazza A, Cazaux D (2000) Gas permeability of geosynthetic clay liners. Geotext Geomembr 18(2-4):235-250. https ://doi.org/10.1016/S0266-1144(99)00029-1

7. Lloret A, Villar MV (2007) Advances on the knowledge of the thermo-hydro-mechanical behaviour of heavily compacted "FEBEX" bentonite. Phys Chem Earth 32(8-14):701-715. https ://doi.org/10.1016/j.pce.2006.03.002

8. Sällfors G, Öberg-Högsta AL (2002) Determination of hydraulic conductivity of sand-bentonite mixtures for engineering purposes. Geotech Geol Eng 20(1):65-80. https://doi. org/10.1023/A:1013857823676
9. Vangpaisal T, Bouazza A (2004) Gas permeability of partially hydrated geosynthetic clay liners. J Geotech Geoenviron Eng 130(1):93-102. https://doi.org/10.1061/ (ASCE) 1090-0241(2004)130:1(93)

10. Villar MV, Lloret A (2004) Influence of temperature on the hydromechanical behaviour of a compacted bentonite. Appl Clay Sci 26(1-4):337-350. https://doi.org/10.1016/j.clay.2003.12.026

11. Abu-Zreig M, Tamimi A (2011) Field evaluation of sand-ditch water harvesting technique in Jordan. Agric Water Manag 98(8):1291-1296. https://doi.org/10.1016/j.agwat.2011.03.008

12. Abu-Zreig $M$, Attom $M$, Hamasha $N(2000)$ Rainfall harvesting using sand ditches in Jordan. Agric Water Manag 46(2):183-192. https://doi.org/10.1016/S0378-3774(00)00082-2

13. Frasier GW, Myers LE (1983) Hand book of water harvesting. U.S. Department of Agriculture. Agriculture handbook no. 600

14. Alim MA, Rahman A, Tao Z, Samali B, Khan MM, Shirin S (2019) Suitability of roof harvested rainwater for potential potable water production: a scoping review. J Clean Prod. https://doi. org/10.1016/j.jclepro.2019.119226

15. Elwell HA, Stocking M (1988) Loss of soil nutrients by sheet erosion is a major hidden farming cost. Zimb Sci News 17:145-147

16. Nyagumbo I, Nyamadzawo G, Madembo C (2019) Effects of three in-field water harvesting technologies on soil water content and maize yields in a semi-arid region of Zimbabwe. Agric Water Manag 216:206-213. https://doi.org/10.1016/j.agwat .2019.02.023

17. Cabalar AF, Akbulut M (2016) Evaluation of actual and estimated hydraulic conductivity of sands with different gradation and shape. SpringerPlus 5:820. https://doi.org/10.1186/s4006 4-016-2472-2

18. Cabalar AF, Akbulut M (2016) Effects of the particle shape and size of sands on the hydraulic conductivity. Acta Geotech Slov 13(2):82-93

19. Ishaku JM, Gadzama EW, Kaigama U (2011) Evaluation of empirical formulae for the determination of hydraulic conductivity based on grain-size analysis. J Geol Min Res 3(4):105-113

20. Goktepe AB, Sezer A (2010) Effect of particle shape on density and permeability of sands. Proc Inst Civ Eng Geotech Eng 163(6):307-320. https://doi.org/10.1680/geng.2010.163.6.307

Publisher's Note Springer Nature remains neutral with regard to jurisdictional claims in published maps and institutional affiliations. 